NASA Technical Memorandum 83694

\title{
Dynamic Stress Analysis of Smooth and Notched Fiber Composite Flexural Specimens
}

P. L. N. Murthy and C. C. Chamis

Lewis Research Center

Cleveland, Ohio

\section{Prepared for the}

Seventh Conference on Composite Materials: Testing and Design sponsored by the American Society for Testing and Materials Philadelphia, Pennsylvania, April 2-5, 1984 
PAGE

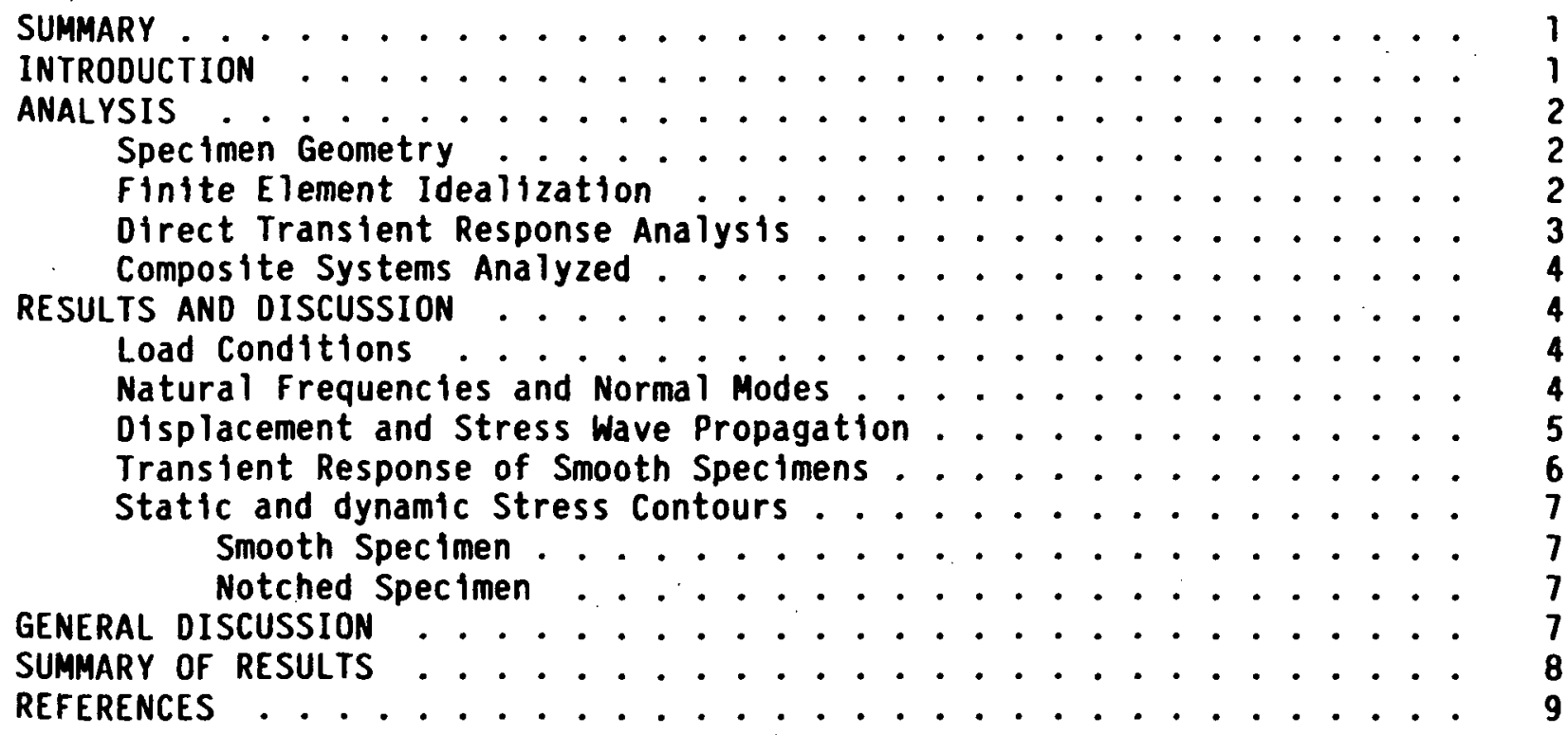


DYNAMIC STRESS ANALYSIS OF SMOOTH AND NOTCHED FIBER

COMPOSITE FLEXURAL SPECIMENS

\author{
P. L. N. Murthy and C. C. Chamis \\ National Aeronautics and Space Administration \\ Lewis Research Center \\ Cleveland, Ohio 44135
}

\title{
SUMMARY
}

A detailed analysis of the dynamic stress field in smooth and notched fiber composite (Charpy-type) specimens is reported in this paper. The analysis is performed with the aid of the direct transient response analysis solution sequence of MSC/NASTRAN. Three unidirectional composites were chosen for the study. They are S-Glass/Epoxy, Kevlar/Epoxy and T-300/Epoxy composite systems. The specimens are subjected to an impact load which is modeled as a trlangular impulse with a maximum of $2000 \mathrm{lb}$ and a duration of $1 \mathrm{~ms}$. The results are compared with those of static analysis of the specimens subjected to a peak load of $2000 \mathrm{lb}$. For the geometry and type of materials studied, the static analysis results gave close conservative estimates for the dynamic stresses. Another interesting inference from the study is that the impact induced effects are felt by S-Glass/Epoxy specimens sooner than Kevlar/Epoxy or T-300/Epoxy specimens.

\section{INTRODUCTION}

Smooth and notched flexural specimen testing continues to be popular in the composites community for characterizing and/or qualifying fiber composites. Reasons for the popularity are: (1) simplicity, (2) adaptability to adverse environments, (3) availability of simple equations for data reduction, and (4) availability of written ASTM standard testing procedures. In addition to these reasons, flexural specimen testing forces the material to respond like a structure by simultaneously subjecting it to tensile, compressive and shear stresses. Furthermore, the notched flexural specimen (Charpy impact test specimen) testing enables easy determination of fracture toughness and impact resistance.

Fracture in general (be it static, quasi-static or dynamic) is a dynamic event and, as such, is a very complex process. Fracture progression in a flexural specimen is controlled by the local dynamic stress field which is also complex. The local dynamic stress field is characterized by the stress waves which are normal, shear, flexural and surface waves. Each of the dynamic stresses can initiate failure (or a defect) at a point and/or propagate this defect to fracture. For a complete understanding of these phenomena a detalled description of the local dynamic stress field is a prerequisite. This requires the use of a complex transient analysis involving direct time integration as opposed to the standard modal synthesis methods such as those available in some general purpose finite element structural analysis codes. Solution 27 (direct transient response) of MSC/NASTRAN is one of the avallable tools for such analyses. The objective of the present paper is to report a detalled analysis of the dynamic stress field in smooth and notched charpy specimens. 
Although the notched Charpy test specimen has been used for years in testing metals and recently in testing composites, no analysis has been performed to determine the detailed dynamic stress state variation in the notch vicinity. In general, the physical problem of the notched charpy test specimen is dynamic and nonlinear; solution of this problem is difficult. However, a good first order approximation may be obtained by assuming linear behavior and a quasistatic load. Reference 1 reports such an analysis which uses the static solution sequence of COSMIC NASTRAN. The main conclusions of reference 1 are: 1) the stress state is blaxial, and 2) the Charpy test specimen is not suitable for assessing the impact resistance of nonmetallic fiber composites directly. In the present work the effort is directed towards understanding the stress wave propagation and the attendant dynamic stress field in fiber composite smooth and notched flexural specimens.

\section{ANALYSIS}

In this section, the specimen geometry, the finite element idealization, the finite element analysis method, and the composite systems analyzed are described.

\section{Specimen Geometry}

The geometry of the Charpy test specimen (ASTM STO E23-7) is shown in figure 1. As can be seen in this figure, the overall length of the specimen is $2.164 \mathrm{in}$. and the length between supports is $1.574 \mathrm{in}$. The specimen widith is $0.394 \mathrm{in}$. The specimen unnotched depth is $0.394 \mathrm{in}$. and the depth at the notch is $0.375 \mathrm{in}$. The notch is $0.079 \mathrm{in}$. deep and has a $45^{\circ}$ opening.

\section{Finite Element Idealization}

Two finite element idealizations of Charpy test specimens -- one without a notch (smooth specimen) and one with a notch were selected for the present study. The details of the meshes are shown in figures 2 and 3 . The material properties are assumed to be uniform, orthotropic, and obey a linear stressstrain law throughout the analysis. In addition, the specimen is assumed to be in a state of plane stress. The plane stress assumption is also justified from the physics of the problem. The width restraints at the notch-tip are negligible because of the very low value of the respective Poisson's ratio. For the present analysis, the plane stress assumption implies that the stresses are permitted to vary along the specimen length and through the thickness but not across the width. This reduces the stresses to be calculated to three, two normal and one shear.

With these assumptions, plane stress finite elements can be used to model the Charpy test specimen. For the smooth specimen all the elements are quadrilateral. The notched specimen is modeled with both triangular elements and quadrilateral elements. The triangular elements are used as transition elements in the areas around the the supports, the load application point and the notch. These are the regions where maximum stress concentrations are expected to occur and therefore are provided with a finer mesh. The boundary conditions prescribed are such that the node at the left support is constrained from $x, y$ and $z$ displacements, and the node at the right support is constrained from $y$ 
and $z$ displacements. In addition, for the notched specimen, three nodes closest to the right support are constrained from displacement in the y direction. The specimens are subjected to an impulse loading. The form of impact is a triangular function with peak load of $2000 \mathrm{lb}$ occuring at 500 us of a total contact time of $1000 \mu \mathrm{s}$.

The statistics of the finite element representation for the smooth and notched specimens are as follows:

1) Smooth Specimens.

Number of nodes or grid points

Number of displacement degrees of freedom (DOF) (2 degrees of freedom per node)

Number of quadrilateral plate elements (CQUAD4)

DOF eliminated using the boundary conditions ( 2 from $u=0$ and $v=0$ at the left support and 1 from $v=0$ at the right support)

Number of free DOF $(2294-3)$

2) Notched Specimens.

Number of nodes or grid points

Number of displacement degrees of freedom (DOF)

Number of quadrilateral plate elements (CQUAD4)

Number of triangular plate elements (CTRIA3)

Total number of elements $(544+82)$

DOF eliminated using the boundary conditions ( 2 from $u=0$ and $v=0$ at the left support and 3 from $v=0$ for three nodes at the right support)

Number of free DOF $(1312-5)$

\section{Finite Element Analysis Method}

The MSC/NASTRAN general purpose structural analysis finite element computer program is used for the finite element analysis. The specific elements used are identified as CTRIA3 and CQUAD4. They are isoparametric constant strain elements. NASTRAN obtains the solution using a displacement formulation via rigid format solution sequence No. 27 . This solution sequence employs a direct time integration scheme to obtain the transient response of a structure.

The solution sequence No. 27 of MSC/NASTRAN uses the integration algorithm based upon the Newmark Beta method (ref. 2). It provides stable results for the widest possible spectrum of practical problems without sacrificing either accuracy or efficiency. For complete detalls of the MSC/NASTRAN analysis (ref. 3) should be consulted. A brief description is given in the following paragraphs.

The differential equations of a linear structural problem may be written in the general matrix form

$$
\left[p^{2} M+p B+K\right]\{U\}=\{F\}
$$

where $p=d / d t$. $M$ and $K$ are the mass and stiffness matrices, $B$ is assoclated with the damping matrix, $u$ is the vector of displacements and $F$ is the load vector. The numerical integration is achieved by replacing $p^{2}$ and $p$ by finite difference operators and then using explicit integration. The 
outputs of the transient analysis module include velocities, and accelerations as well as displacements. The output can be requested at even multiples of the integration time step. This feature affords some economy in output data preparation in cases where small time step is needed for greater accuracy.

\section{Composite Systems Analyzed}

Flexural (Charpy-type) test specimens made from three typical composite systems are analyzed. They are: T-300/Epoxy, Kevlar/Epoxy, and S-Glass/Epoxy composites. The specimens are all unidirectional composites with the fibers parallel to the length (x-axis, fig. 1) of the specimen.

The plane stress-strain relationship (stiffness) coefficients required to input to NASTRAN are summarized in table 1 . These properties are obtained by using the resident data-bank in the composite mechanics computer code ICAN (ref. 4). The relationships between the NASTRAN stiffness coefficients (G's), and the usual engineering constants are:

$$
\begin{aligned}
& G_{11}=E_{\ell 11} /\left(1-v_{\ell 12} v_{\ell 21}\right) \\
& G_{12}=v_{\ell 21} G_{11}=v_{\ell 12} G_{22}=G_{21} \\
& G_{22}=E_{\ell 22} /\left(1-v_{\ell 12} v_{\ell 21}\right) \\
& G_{33}=G_{\ell 12} \\
& G_{13}=G_{23}=G_{31}=G_{32}=0
\end{aligned}
$$

The notation in equations (2) to (5) is as follows: $E_{\ell} l 1$ denotes the longitudinal modulus, $E_{\ell 22}$ the transverse modulus, $G_{\ell 12}$ the shear modulus, $v_{\ell 12}$ the major Poisson's and v221 the minor Poisson's ratios. For an elastic material the two Poisson's ratios are related by the well known relation

$$
v_{\ell 21}=v_{\ell 12} E_{\ell 22} / E_{\ell 11}
$$

RESULTS AND DISCUSSION

\section{Load conditions}

Two types of load conditions are used in obtaining the results. The first is a static loading where a force of $2000 \mathrm{lb}$ is applied at the center of the specimen on the top surface. The second is an impulse loading. This is modeled as a triangular pulse with a peak value of $2000 \mathrm{lb}$ in the middle. The pulse is modeled to last for $1000 \mu \mathrm{s}$. The transient response is, however, obtained for three contact time periods (i.e., $3 \mathrm{~ms}$ ). A separate normal modes analysis is used to determine the first five natural frequencies.

\section{Natural Frequencles and Normal Modes}

The NASTRAN normal modes analysis module (Solution 3 ) is utilized to determine the first five natural frequencies and the associated mode shapes for 
the charpy test specimens. They are shown in figure 4. The results are shown in table II for S-Glass/Epoxy specimens. The frequencies are used to determine the time periods which aid in determining the integration time step for the transient analysis. A time step of $5 \mu \mathrm{s}$ is chosen for the transient analysis based upon the time perlods shown in table II.

\section{Displacement and Stress Wave Propagation}

The bulk wave and shear wave velocities are normally much higher compared to the flexural wave velocities. In order to capture the characteristics of propagation of these waves a much smaller time step of integration $(0.1 \mu \mathrm{s})$ is chosen. The output of displacements and stress contours at various time intervals are saved and displayed graphically in figures 5 to 10 . Figures 5 to 7 depict the dynamic displacement propagation in S-Glass/Epoxy, Kevlar/Epoxy and T-300/Epoxy specimens. Two bulk wave velocity parameters and one shear wave velocity parameter are defined below to ald the following discussion of the displacement wave propagation results:

$$
\begin{aligned}
& C_{B 11}=G_{11 / p} \\
& C_{B 22}=G_{22^{/ P}} \\
& C_{S 12}=G_{12^{/ P}}
\end{aligned}
$$

where $\rho$ is the mass density of the material.

The computed values of $C_{B 11}, C_{B 22}$, and $C_{S 12}$ are shown in table III for the three composite systems under study. The velocities are expressed in in./ps. The trend indicated by $\mathrm{C}_{B 22}$ for the three materials (the transverse shock wave travels fastest in S-Glass/Epoxy and slowest in Kevlar/Epoxy) is seen clearly in figures 5 to 7 specifically the frames after 3 and $5 \mu \mathrm{s}$. A rough estimate of the normal wave velocity can be obtained by counting the number of elements that appear to be affected by the impact from the figures 5 to 7. The normal wave velocity estimates from the 1 and $3 \mathrm{sec}$ frames are shown below:

\begin{tabular}{lccccc} 
Composite system & Number of elements & \multicolumn{2}{c}{ Velocity } & Average \\
& $1 \mu \mathrm{sec}$ & $3 \mu \mathrm{sec}$ & $1 \mu \mathrm{sec}$ & $3 \mu \mathrm{sec}$ & \\
& & & & & \\
S-Glass/Epoxy & 10 & 25 & 0.1313 & 0.1094 & 0.1204 \\
T-300/Epoxy & 7 & 16 & .0788 & .0700 & .0744 \\
Kevlar/Epoxy & 5 & 12 & .0657 & .0520 & .0589
\end{tabular}

These values are in close agreement with the theoretical values shown in table III under $C_{B 22}$. The same trend is also seen for the 3 and $5 \mu \mathrm{sec}$ frames. It can be concluded that the initial shock travels with the bulk wave velocity $C_{B 22}$ along the direction of impact.

Once the normal shock reaches the bottom of the beam, the wavefront appears to be moving in the longitudinal direction forming a flexural wave. The velocities of the waves traveling in the longitudinal direction can also be determined approximately with the same technique mentioned earlier. The following are the details for the frame after $13 \mu \mathrm{s}$ : 
Composite system Number of Velocity

elements

$\begin{array}{lrr}\text { S-Glass/Epoxy } & 11 & 0.0510 \mathrm{in} / \mu \mathrm{sec} \\ \text { T-300/Epoxy } & 9 & .0416 \mathrm{in} / \mu \mathrm{sec} \\ \text { Kevlar/Epoxy } & 7 & .0320 \mathrm{in} / \mu \mathrm{sec}\end{array}$

The above velocities appear to have the same trend as depicted by the wave velocity parameter $\mathrm{C}_{S 12}$ shown in table III. However, the waves along the iongitudinal direction appear to move significantly slower than that indicated by $C_{512}$. This is probably due to the coupling between the flexural wave and the shear wave. The flexural wave velocity is signiffcantly slower than the shear wave velocity. For example, the smooth S-Glass/Epoxy specimen under study has a flexural wave velocity given by

$$
C_{F}=2 \ell f=0.0137 \mathrm{in} / \mu \mathrm{sec}
$$

where $\ell$ is the length between the supports, $f$ is the first fundamental frequency. (It is assumed that the wave number is 1 and the beam deflects into a half wave.)

The transient stress response after one percent (10 $\mu \mathrm{s})$ of the contact time are shown in figures 8 to 10 in the form of stress contours. All stresses are localized at this early time. The longitudinal stress $(0,1)$ in the Kevlar/Epoxy and T-300/Epoxy composites is of about the same magnitude while that in the S-Glass/Epoxy is about half as much. The normal stress $\left(\sigma_{22}\right)$ and shear stress $\left(0_{12}\right)$ are of about the same magnitude for all three composite systems. It appears from these stress results that, under the same impact conditions, the stress in the Kevlar/Epoxy and the T-300/Epoxy will reach fiber fracture stress magnitudes considerably earlier (about half the time) than in the S-Glass/Epoxy composite. Two implications follow relative to the same stress magnitude: (1) the S-Glass/Epoxy composite will sustain greater impact load prior to fracture than the T-300/Epoxy, and (2) the rapld compressive stress built up will cause longitudinal compression fallure accompanied by substantial bending deflection in the Kevlar/Epoxy composite thus increasing the impact required to induce fracture.

\section{Transient Response of Smooth Specimens}

The displacements, velocities, accelerations and stresses are obtained for a total contact time of $1000 \mu \mathrm{s}$ for S-Glass/Epoxy smooth specimens. In these computations a time step of $5 \mu \mathrm{s}$ is used. The output is saved for every two time steps. Two points $A$ and $B$ as shown in figures 2 and 3 are selected for study. A is the load point and $B$ is the opposite point at the bottom for smooth and at the notch-tip for notched specimens.

The transient response results appear in figures 11 to 16 . Figures 11 to 13 show the longltudinal (axial) and the transverse (bending/flexural) components of displacement, velocity and acceleration of point $A$ plotted against time. The corresponding results for point $B$ are not shown as they are similar to point $A$ response both qualitatively and quantitatively. It can be concluded from these figures that the response is primarliy in the first flexural mode. For example (from fig. 11) the number of cycles in $1 \mathrm{~ms}$ is counted as a little 
over 6. From table II the first fundamental time period is $161.3 \mu \mathrm{s}$ which implies that $6.2(1000 / 161.3)$ cycles of response in first mode can be expected.

The stress response results are shown graphically in figures 14 to 16 . Each figure contains the stress response of elements near points $A$ and $B$. The longitudinal stress behavior appear to be primarily the first flexural mode response. However, the magnitude of stress near point $A$ is about one and a half times greater than the magnitude of stress near point $B$. This is to be expected because of stress concentration near the load point $A$. The transverse normal $\left(\sigma_{22}\right)$ and the shear $\left(\sigma_{12}\right)$ stress increase linearly to a peak when the load takes the maximum value of $2000 \mathrm{lb}$ and then decrease innearly to a zero. The corresponding stresses for the element near point $B$ are insignificant and therefore can not be shown distinctly when drawn to the same scale.

The response after the load removal is not shown in the above figures. The computations, however, are conducted for three contact time periods. It is found that, for all practical purposes, the specimen remains static. A typical response curve is shown in figure 17 for point $A$.

\section{Static and Dynamic Stress Contours}

Smooth specimen. - The static stress contours under a load of $20001 \mathrm{~b}$ and the dynamic stress contours at the peak load of $2000 \mathrm{lb}$ are shown in figures 18 to 20. They appear to be identical. The peak values for the dynamic load case, however, are slightly lower than those for the static case. While the maxima for the longitudinal stress $(\sigma 11)$ occur at the center of top and the bottom, the transverse normal stress and the transverse shear stress have the maxima almost adjacent to each other near the load application point. The transverse shear stress and the axial stress distribution is seen to approach the classical Euler-Bernoulli theory predictions away from the load application point. Steep stress gradients are observed near the load application point.

Notched specimen. - The results for notched S-Glass/Epoxy specimen are shown in figures 21 to 23 . The static and dynamic stress contours at the peak load show similar trend as observed in the case of smooth specimens. Figure 24 shows the stress intensity near notch-tip in relation to the far field stresses. This distance from the notch-tip is measured along the longitudinal direction towards the left support. It is seen that all the three stresses attain very high peaks, indicating severe local stress intensities near the notch-tip. As the stress allowables for $\sigma_{22}$ and $\sigma_{12}$ are generally an order of magnitude lower than that for 011 , one can expect a matrix initiated fal1ure followed by fiber fractures at this location.

\section{GENERAL DISCUSSION}

The response analys is of smooth and notched Charpy-type flexural specimens subjected to a triangular impulsive load provides insight into the nature of stress wave propagation, fallure mechanisms and the relation between the static and dynamic responses. The contact time of the impact load is approximately 6 time periods of the first flexural mode. The bulk wave velocities $C_{B} l l$ and $\mathrm{C}_{\mathrm{B} 22}$, and the shear wave velocity $\mathrm{C}_{\mathrm{S} 72}$ are very high compared to the flexural wave velocity for the materials and the geometry under study. Hence, the response is observed at early times of the impact event (of the order of a microsecond). It shows that the initial waves travel with a bulk wave velocity 
$C_{B 22}$ till they reach the bottom surface of the specimen. The waves then appear to travel longitudinally towards the supports. The approximate calculations based upon the deformations at various times indicated that the wave velocity is significantly lower than the shear wave velocity $C_{S 12}$ but much higher than the flexural wave velocity. The wavefront appears to induce a flexural wave as it progresses towards the supports.

At longer times, the response is primarily in the first flexural mode. A comparison with the static response indicates that little or no difference exists in the magnitude for stresses at the peak load. The static predictions, however, are on the conservative side.

The response of notched fiber composite specimens show severe stress intensities near the notch region indicating local fallures in shear and transverse tension inftially followed by fiber fractures since the longitudinal stresses approach fracture stress magnitudes.

The response after the load removal reduces to mere noise; the structure remains practicaliy static.

\section{SUMMARY OF RESULTS}

The results of the study on static, dynamic and transient response of smooth and notched, fiber composite, Charpy specimens are listed below:

(i) The wave propagation velocities can be estimated from the early time displacement propagation response; the estimates are in fair agreement with the theoretical predictions.

(2) The first five flexural mode shapes and frequencies show coupling effects from the thickness stretch and the transverse shear type modes; the frequencies are not integer multiples of the fundamental frequency.

(3) The dynamic and static peak load stress contours are almost identical. The static peak load stress magnitudes are slightly higher. Stress predictions based upon a quasi-static approach lead to conservative estimates.

(4) The transient displacement and velocity response appear to be primarlly in the first flexural mode. The acceleration response shows contributions from higher modes.

(5) The structure responds for the load duration time period only. The steady state response after the load removal appears to be negligible.

(6) The transverse normal and shear stresses vary linearly with time and follow the load path.

(7) The notch-tip region develops severe stress concentrations and any of the three stresses could cause or initiate a fallure.

(8) Based upon the transient stress response, it appears that the failures in Charpy specimens are initiated at the notch-tip by the shear stresses and the transverse tensile stresses followed by fiber fractures. However, the 
fallures in smooth specimens are probably initiated by a combined stress state near the load application point followed by local interply delaminations.

\section{REFERENCES}

1. Chamis, C. C., "Faflure Mechanics of Fiber Composite Notched Charpy Specimens," NASA TM X-73462, National Aeronautics and Space Administration, Lewis Research Center, Cleveland, OH, Sept. 1976.

2. Newmark, N. M., American Society of Civil Engineers, Journal of the Engineering Mechanics Division, EM-3, July 1959, pp. 67-94.

3. MacNeal, R. H., "The NASTRAN Theoretical Manual, (Level 15.5), "MacNealSchwendier Corp., Los Angeles, CA, Dec. 1972.

4. Murthy, P. L. N. and Chamis, C. C., "ICAN: Integrated Composite Analyzer: Users and Programmers Manuals, NASA TP; No. to be assigned, National Aeronautics and Space Administration, Lewis Research Center, Cleveland, $\mathrm{OH}, 1984$. 
TABLE I. - NASTRAN PLANE STRESS - STRAIN RELATIONSHIPS

\begin{tabular}{|c|c|c|c|c|c|c|c|}
\hline \multirow{2}{*}{$\begin{array}{l}\text { Composite } \\
\text { system }\end{array}$} & \multirow{2}{*}{$\begin{array}{l}\text { Mass density } \\
\left(\times 10^{4}\right) \\
\left(1 b . \sec ^{2} / \text { in }^{4}\right)\end{array}$} & \multicolumn{3}{|c|}{ Stress-strain coefficient } & \multicolumn{3}{|c|}{ Orthotropy Ratios } \\
\hline & & $G_{11}$ & $G_{12}=G_{21}$ & $\begin{array}{c}\mathrm{G}_{22} \\
\left(\times 10^{6} \mathrm{ps} 1\right)\end{array}$ & $G_{33}$ & $G_{11^{/}} G_{22}$ & $G_{11} / G_{33}$ \\
\hline $\begin{array}{l}\text { S-Glass } \\
\text { /Epoxy }\end{array}$ & 1.813 & 8.7900 & 1.1700 & 3.2600 & 1.2700 & 2.70 & 6.92 \\
\hline $\begin{array}{l}\text { Kevlar } \\
\text { /Epoxy }\end{array}$ & 1.249 & 12.385 & .20082 & .57377 & .31635 & 21.59 & 39.15 \\
\hline $\begin{array}{l}T-300 \\
/ \text { Epoxy }\end{array}$ & 1.405 & 17.896 & .30275 & 1.1378 & .50871 & 15.81 & 35.18 \\
\hline
\end{tabular}

TABLE II. - NATURAL FREQUENCIES AND TIME

PERIODS FOR S-GLASS/EPOXY SMOOTH ANO NOTCHED SPECIMENS

\begin{tabular}{|c|c|c|c|}
\hline $\begin{array}{c}\text { Spectmen } \\
\text { type }\end{array}$ & $\begin{array}{c}\text { Mode } \\
\text { number }\end{array}$ & $\begin{array}{c}\text { Frequency } \\
\text { (cycles/sec) }\end{array}$ & $\begin{array}{c}\text { Time pertod } \\
\text { ( } \mathrm{s} \text { ) }\end{array}$ \\
\hline Smooth & 1 & 6200.67 & 167.3 \\
& 2 & 11659.54 & 85.8 \\
& 3 & 19993.02 & 50.2 \\
& 4 & 37062.8 & 32.2 \\
Notched & 5 & 43913.02 & 22.8 \\
& 1 & 9030.16 & 110.7 \\
& 2 & 14631.33 & 68.3 \\
& 3 & 24596.56 & 40.7 \\
& 4 & 27775.86 & 36.0 \\
& 5 & 36685.27 & 27.3 \\
\hline
\end{tabular}


TABLE III. - WAVE VELOCITY PARAMETERS

FOR THE SELECTED COMPOSITE SYSTEMS

\begin{tabular}{|l|r|r|r|}
\hline Parameter & $C_{B 11}$ & $C_{B 22}$ & $C{ }$ S12 \\
\hline Saterlal & & & \\
\hline Kevlass/Epoxy & 0.2201 & 0.1341 & 0.0837 \\
T-300/Epoxy & .3149 & .0678 & .0503 \\
\hline
\end{tabular}




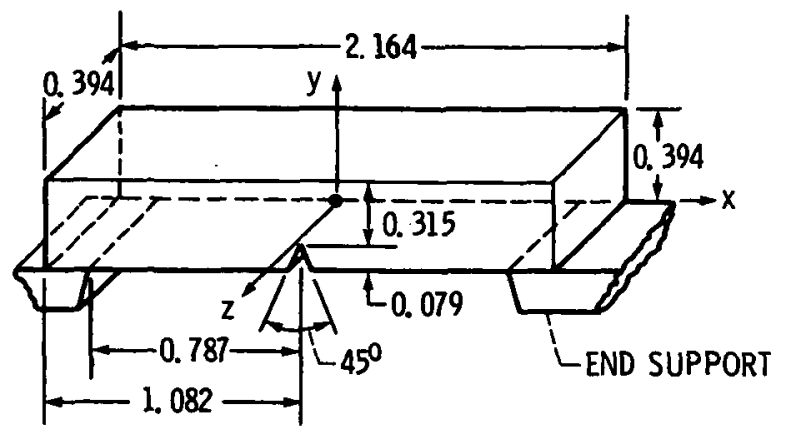

Figure 1. - Geometry of ASTM Charpy test specimen. (All dimensions in inches.)

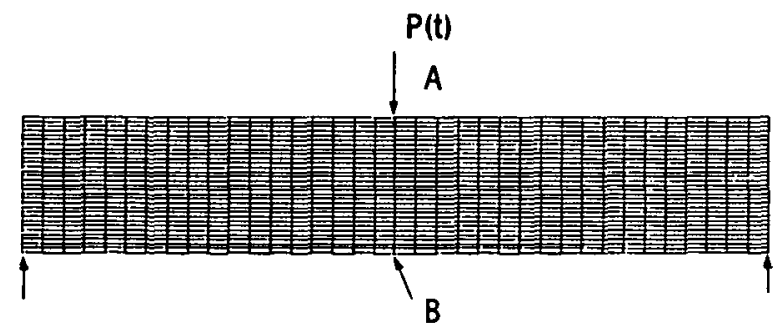

Figure 2. - Finite element idealization of smooth specimen. 


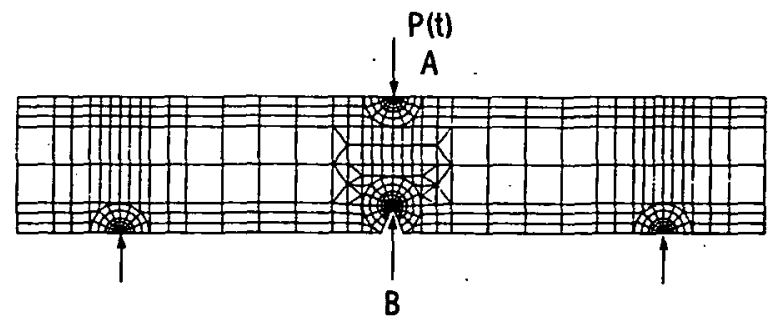

Figure 3. - Finite element idealization of notched Charpy specimen.

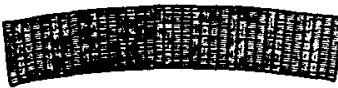

L. $f=6200.67 \mathrm{~Hz}$.

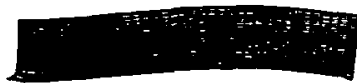

2. $f=11659.54 \mathrm{~Hz}$.

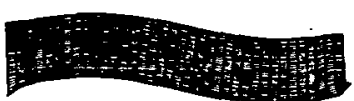

3. $f=19993.02 \mathrm{~Hz}$.

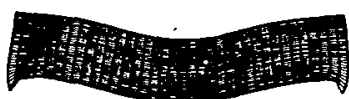

4. $f=31062.80 \mathrm{~Hz}$.

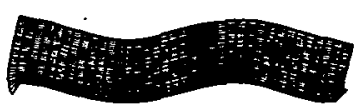

5. $f=43913.02 \mathrm{~Hz}$.

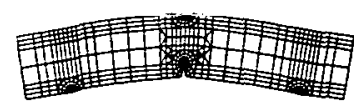

l. $f=9030.15 \mathrm{~Hz}$.

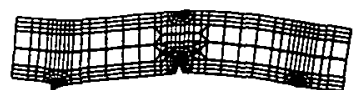

2. $f=14631.33 \mathrm{~Hz}$.

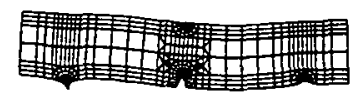

3. $f=245 \% .56 \mathrm{~Hz}$

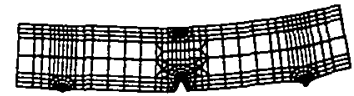

4. $f=27775.86 \mathrm{~Hz}$

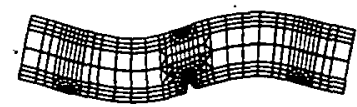

5. $f=36685.27 \mathrm{~Hz}$.

Figure 4 - Natural frequencies and mode shapes for $\mathrm{S}$-glass/epoxy smooth and notched flexural specimens. 


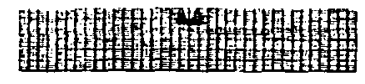

$1 \mu \mathrm{sec}$

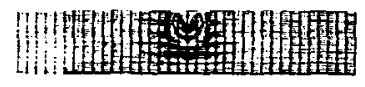

$3 \mu \mathrm{sec}$

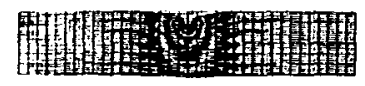

5 usec

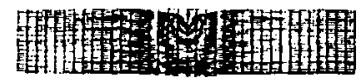

$6 \mu \mathrm{sec}$

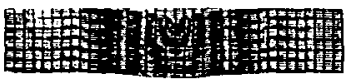

$9 \mu \mathrm{sec}$
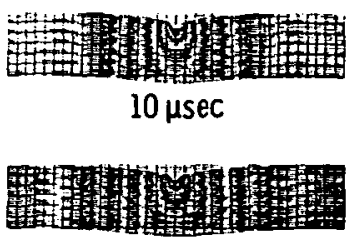

$13 \mu \mathrm{sec}$

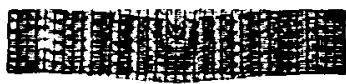

$15 \mu \mathrm{sec}$

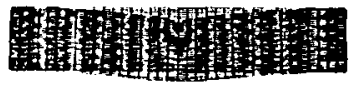

$18 \mu \mathrm{sec}$

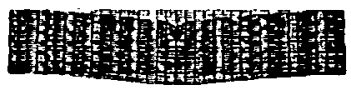

$20 \mu \mathrm{sec}$

Figure 5. - Dynamic displacement propagation in S-glass / epoxy composite flexural specimen. (Triangular impulse: 2000 ib maximum $1000 \mu s e c$ duration. )

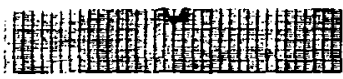

$1 \mu \mathrm{sec}$

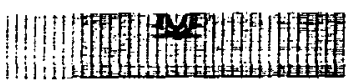

$3 \mu \mathrm{sec}$

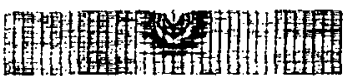

5 usec

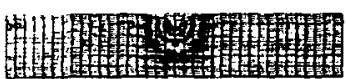

$6 \mu \mathrm{sec}$

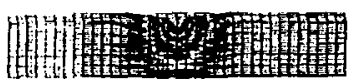

$9 \mu \mathrm{sec}$

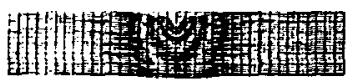

$10 \mu \mathrm{sec}$

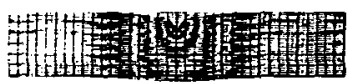

$13 \mu \mathrm{sec}$

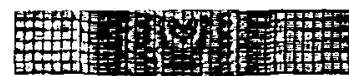

15 usec

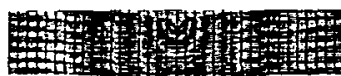

$18 \mu \mathrm{sec}$

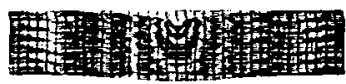

$20 \mu \mathrm{sec}$

Figure 6. - Dynamic displacement propagation in Kevlar I epoxy composite flexural specimen. Triangular impulse: $2000 \mathrm{lb}$ maximum $1000 \mu \mathrm{sec}$ duration. ) 


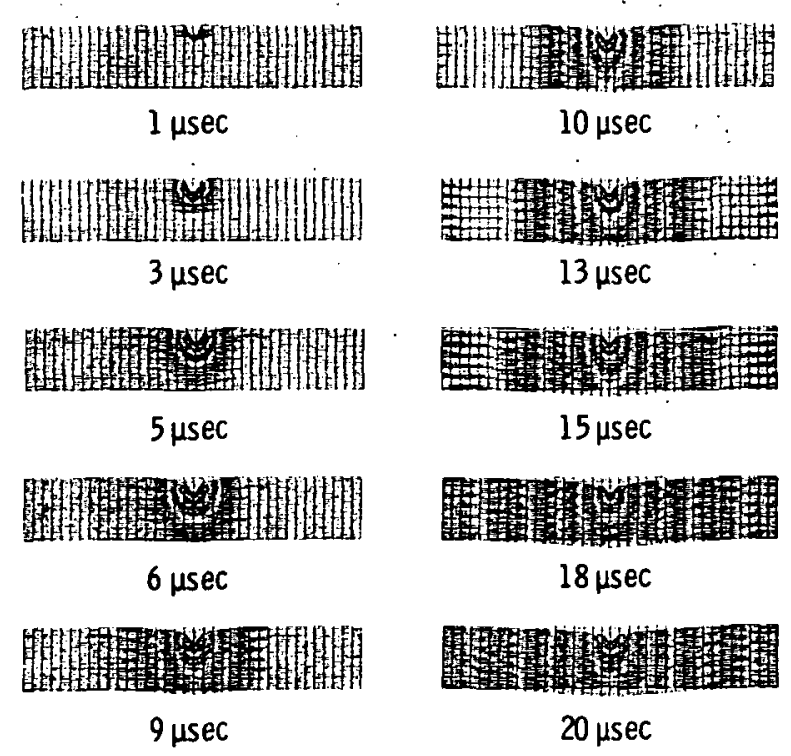

Figure 7. - Dynamic displacement propagation in T-300/ epoxy composite flexural specimen. (Triangular impulse: $2000 \mathrm{lb}$ maximum $1000 \mu \mathrm{sec}$ duration. ) 
SYMBOL VALUES, pSi

$1-1.328899 E+03$

$2-1.143674 E+03$

$3-9.584489 E+02$

$4-7.732237 E+02$

$5-5.879985 E+02$

$6-4.027733 E+02$

$7-2.175482 E+02$

$8-3.232298 E+01$

$9 \quad 1.529022 \mathrm{E}+02$

$103.381274 E+02$

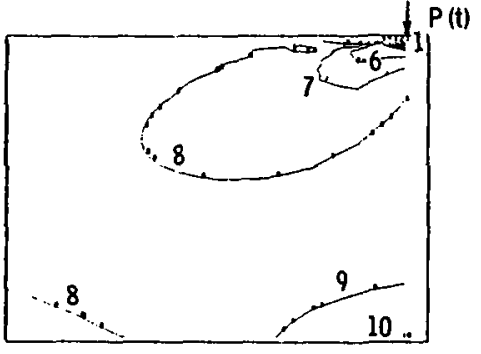

(a) $\sigma_{11}$ Contours.

$1-1.052444 E+03$

$2-9.068754 E+02$

$3-7.613066 \mathrm{E}+02$

$4-6.157379 E+02$

$5-4.701691 \mathrm{E}+02$

$6 \quad 3.246003 E+02$

7 1.790316E+02

$83.346283 E+01$

$9 \quad 1.121059 \mathrm{E}+02$

$10 \quad 2.576747 \mathrm{E}+02$

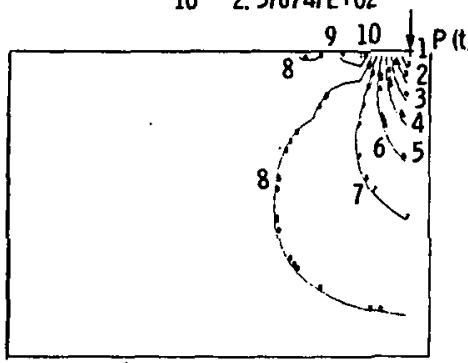

(b) $\sigma_{22}$ Contours.

$1-5.760680 \mathrm{E}+02$

$2-4,970201 E+02$

$3-4.120802 E+02$

$4-3.689114 E+02$

$5-2.998825 E+02$

$6-1.808336 \mathrm{E}+02$

$7-1.017847 \mathrm{E}+02$

$8-2.273584 E+01$

$9 \quad 5.631304 \mathrm{E}+01$

$10 \quad 1.353619 E+02$

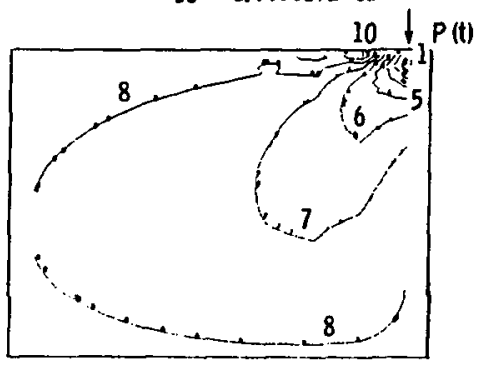

(c) $\sigma_{12}$ Contours.

Figure 8 - Dynamic stress contours in S-glass/epaxy composite flexural specimen after 1 percent contact time.
SYMBOL VALUES. psi

$1-2,362948 E+03$

$2-2.065930 \mathrm{E}+03$

$3-1.768912 \mathrm{E}+03$

$4-1.471895 E+03$

$5-1,174877 \mathrm{E}+03$

$\begin{array}{lll}6 & -8 & 778589 \mathrm{E}+02\end{array}$

$7 \quad-5.308411 E+02$

$8-2.838233 E+02$

9 1. $319453 E+01$

10 3. $102123 \mathrm{E}+02$

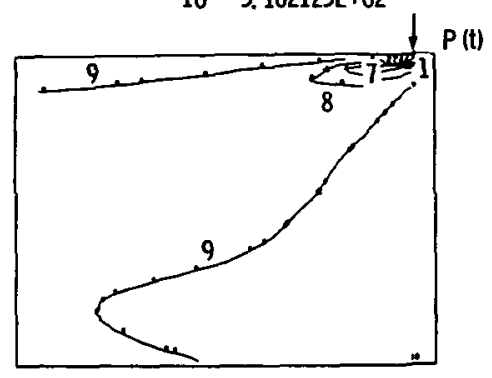

(a) $\sigma_{11}$ Contours.

$1-1.913533 \mathrm{E}+03$

$2-8.775216 \mathrm{E}+02$

$3-7.415100 \mathrm{E}+02$

$4-6.054945+02$

$5-4.694862 E+02$

$6-3.334752 E+02$

$7-1.974635 x+02$

$8-6.145193 E+01$

$97.455 \% 9 \mathrm{E}+01$

$10 \quad 2.10513 E+02$

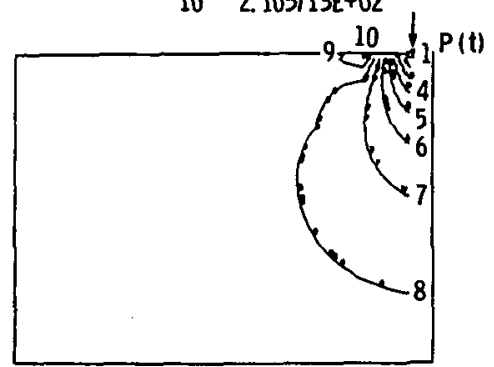

(b) $\sigma_{22}$ Contours.

$17.771991 \mathrm{E}+02$

2 -6. $946070 \mathrm{E}+02$

$3-5.920160 E+02$

$4-4.994229 E+02$

$5-4.068309 \mathrm{E}+02$

$6-3.142388 E+02$

$7-2.216468 E+02$

$8-1.290548 \mathrm{E}+02$

$9-3.646273 E+01$

$10 \quad 5.612931 \mathrm{E}+01$

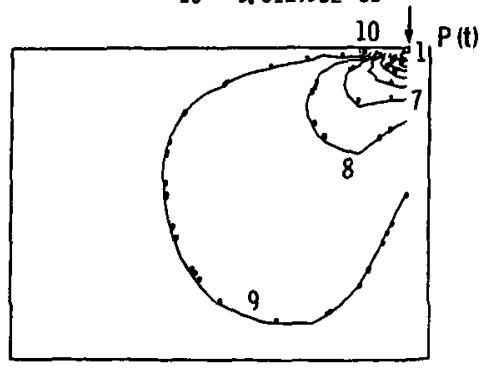

(c) $0_{12}$ Contours.

Figure 9. - Dynamic stress contours in Kevlar/epoxy composite flexural specimen after I percent of the contact time. 
YMBOL VALUES, pSi

1 -2. 200180E+03

$2-1,907888 E+03$

$3-1.615597 E+03$

$4-1.323305 E+03$

$5-1.031014 E+03$

$6-7,387221 \mathrm{E}+02$

$7-4$ 464305E +02

$8-1.541389 E+02$

9 1, 381526E+02

$104304442 E+02$

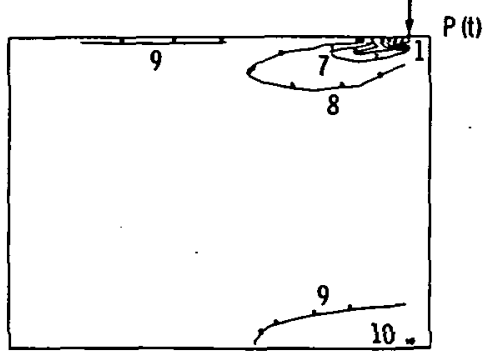

(a) $\sigma_{11}$ Contours.

$\begin{array}{rr}1 & -1.019117 \mathrm{E}+03 \\ 2 & -8.816818 \mathrm{E}+02 \\ 3 & -7.442470 \mathrm{E}+02 \\ 4 & -6.068122 \mathrm{E}+02 \\ 5 & -4.693774 \mathrm{E}+02 \\ 6 & -3.319426 \mathrm{E}+02 \\ 7 & -1.945078 \mathrm{E}+02 \\ 8 & -6.707301 \mathrm{E}+01 \\ 9 & 8.036180 \mathrm{E}+01 \\ 10 & 2.177966 \mathrm{E}+02\end{array}$

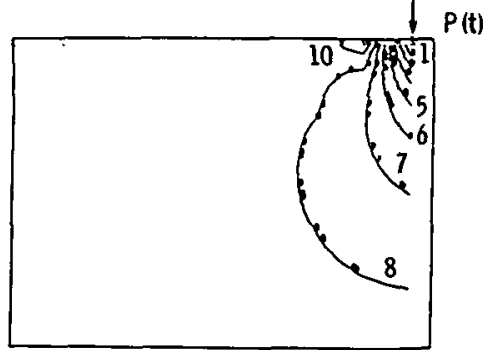

(b) $\sigma_{22}$ Contours.

$1-7.026985 E+02$

$2-6.178950 E+02$

$3-5.830914 E+02$

$4-4,482878 \mathrm{E}+02$

$5-3,634842 E+02$

$6-2.786306 \mathrm{E}+02$

$7-1.938771 \mathrm{E}+02$

$8-1.090725 E+02$

$9-2.426991 E+01$

$10 \quad 6.053367 \mathrm{E}+01$

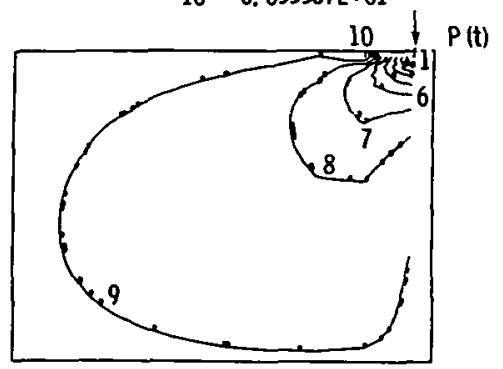

(c) $\mathrm{O}_{12}$ Contours.

Figure 10 - Dynamic stress contours in T-300/epoxy composite flexural specimen after 1 percent contact time. 

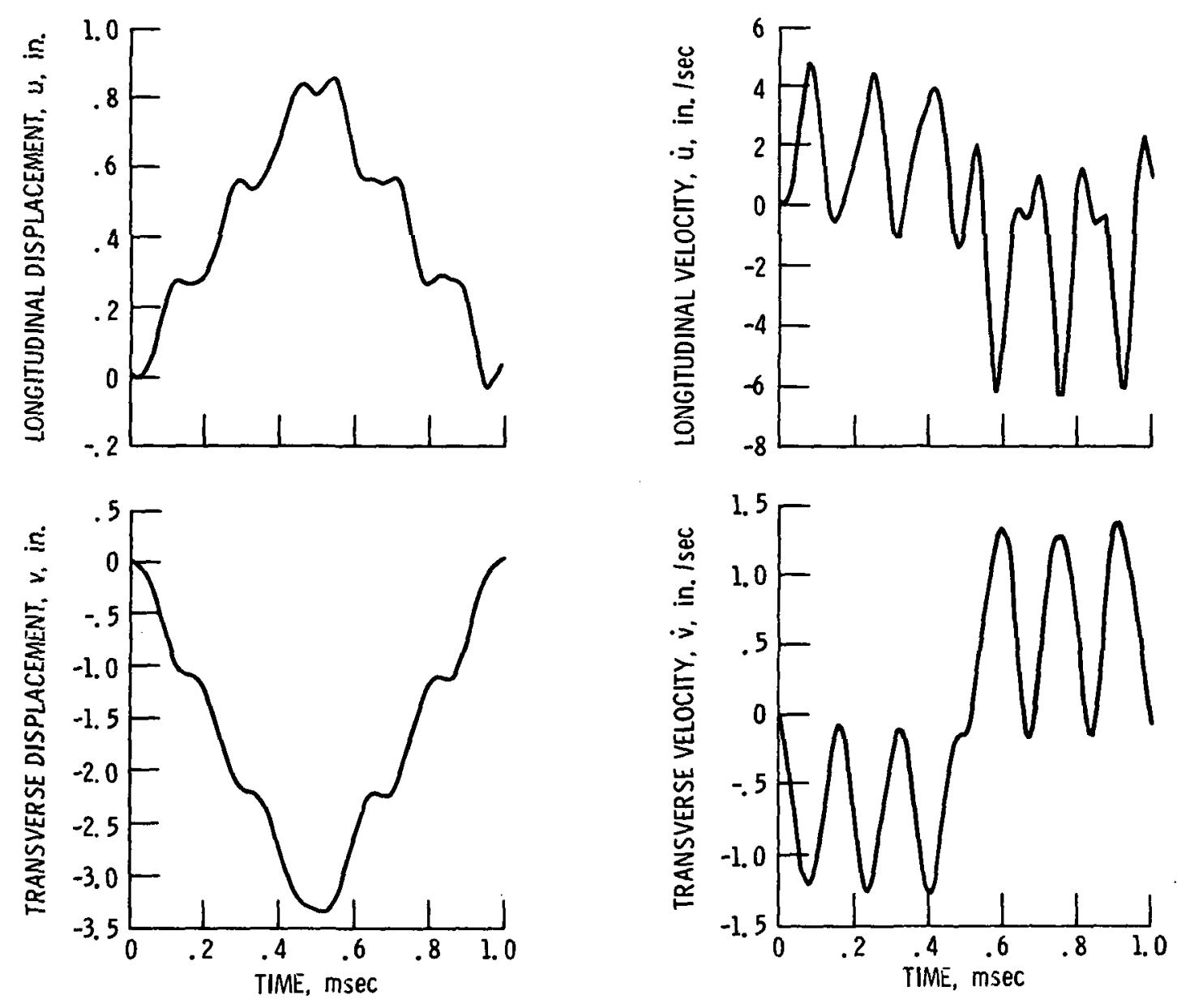

Figure 11. - Displacement response of point A for S-glass/epoxy smooth flexural specimen.

Figure 12. - Velocity response of point $A$ for S-glass/epoxy smooth flexural specimen. 

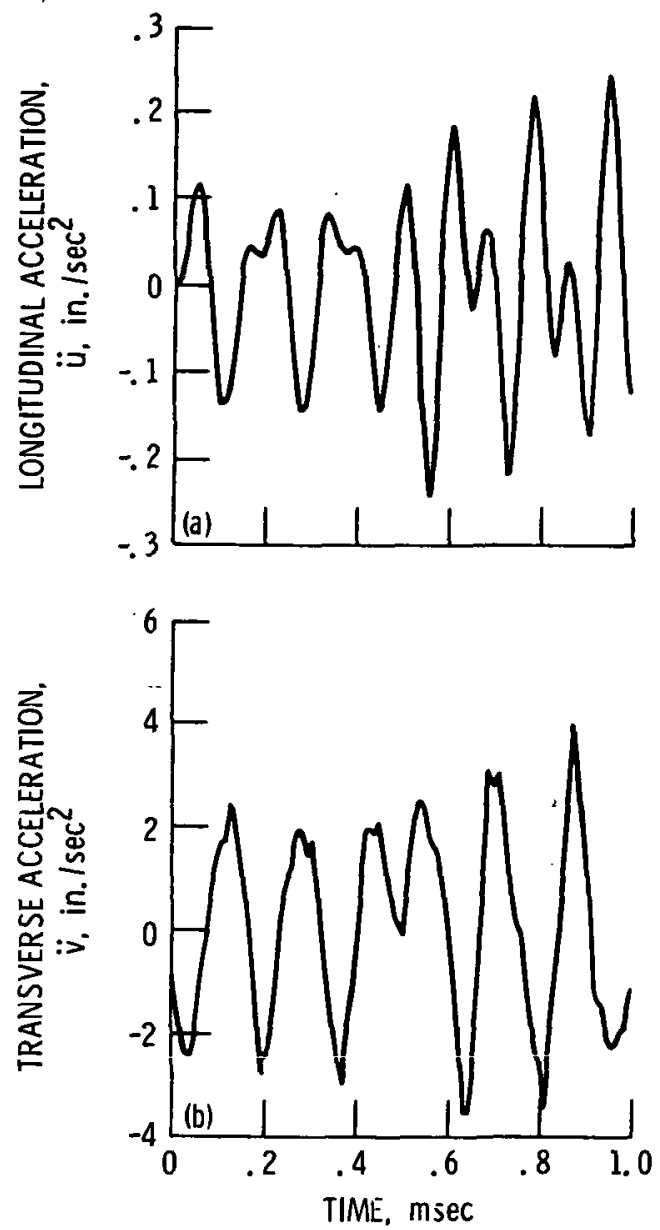

Figure 13. - Acceleration response for S-glass/epoxy smooth flexural specimen.

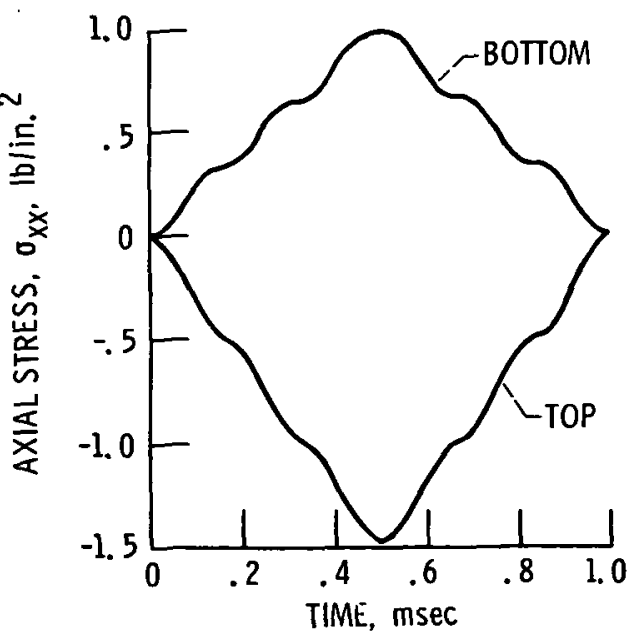

Figure 14. - Axial stress $\sigma_{x x}$ response of top and bottom elements near points $A$ and $B$ for $S$-glass $I$ epoxy smooth flexural specimen. 


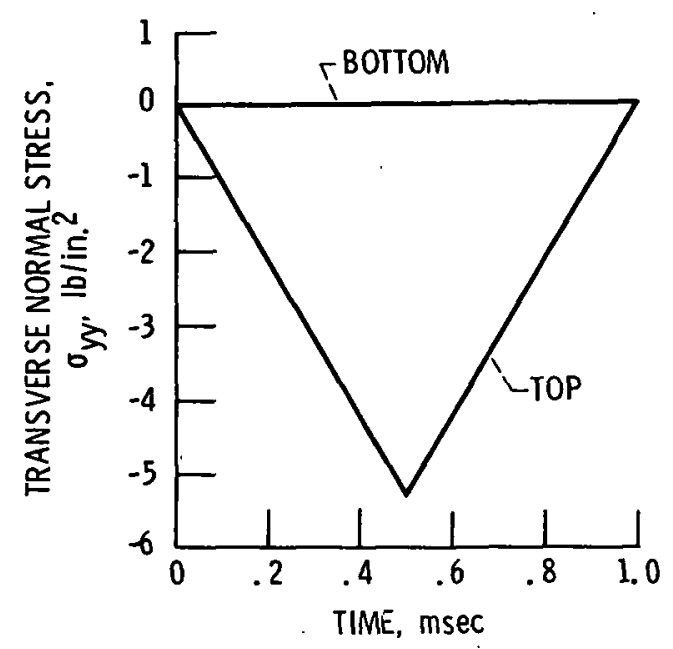

Figure 15. - Transverse normal stress $\sigma_{y y}$ response of top and bottom elements near points $A$ and $B$ for S-glass/epoxy smooth flexural specimen.

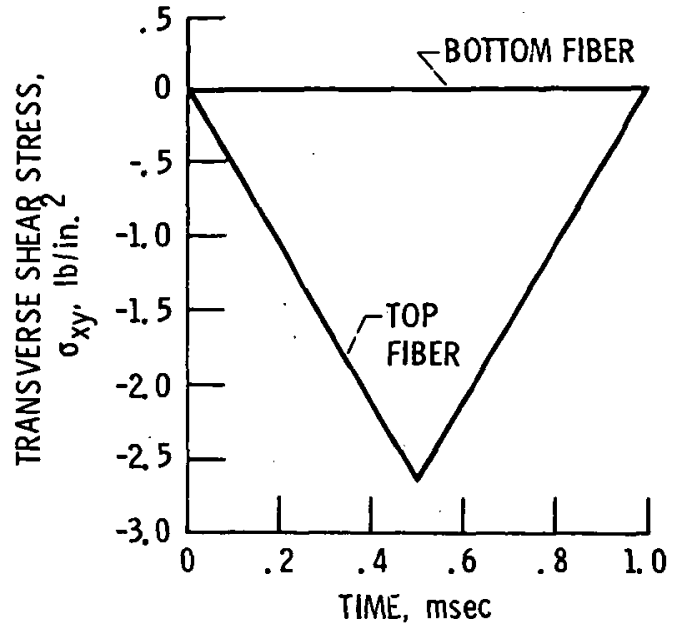

Figure 16. - Transverse shear stress $\sigma_{x y}$ response of top and bottom elements near points $A$ and $B$ for $S$-glass/epoxy smooth flexural specimen.
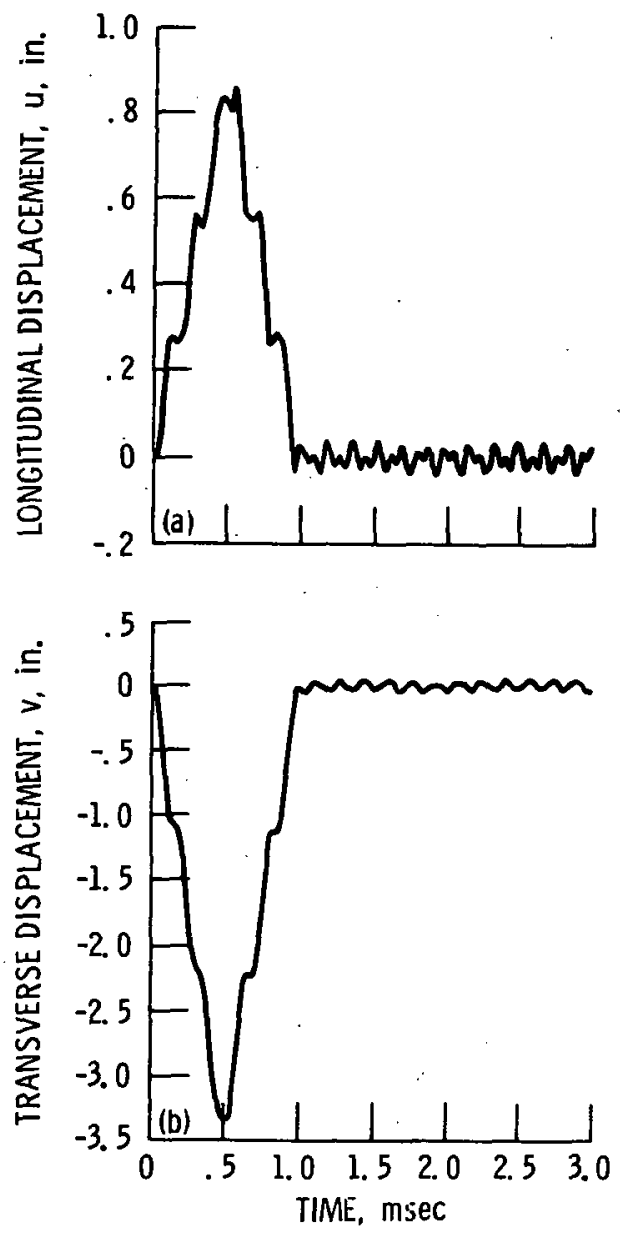

Figure 17. - Displacement response of point $A$ for three contact time periods of S-glass/epoxy smooth flexural specimen. 
SYMBOL VALUES, pSi

$1-1.494680 E+05$

$2-1.216115 E+05$

$3-9.3754 \% \mathrm{E}+04$

$4-6.589843 E+04$

$5-3.804191 E+04$

$6-1.018539 E+04$

7 1. $767114 E+04$

$8 \quad 4.552766 \mathrm{E}+04$

$97.338418 \mathrm{E}+04$

$10 \quad 1.012407 \mathrm{E}+05$

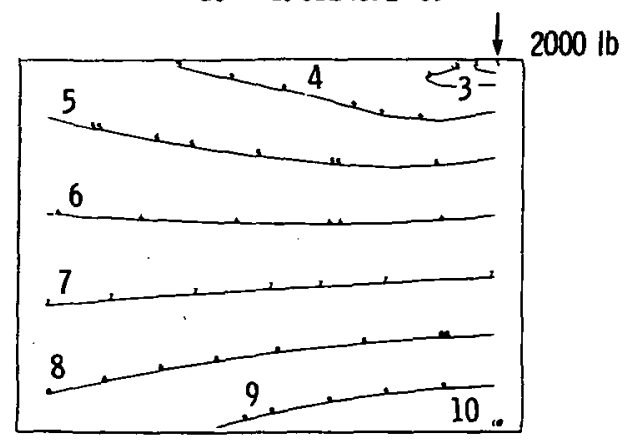

(a) Static stress contours.

$1-1.480251 E+05$

2 -1. 205350E+05

3 -9. 304484E+04

$4 \quad 6.555471 E+04$

$5-3.806458 E+04$

$6-1.057445 E+04$

$7 . \quad 1.691569 \mathrm{E}+04$

$8 \quad 4.440582 E+04$

$97.189595 \mathrm{E}+04$

$10 \quad 9.938608 \mathrm{E}+04$

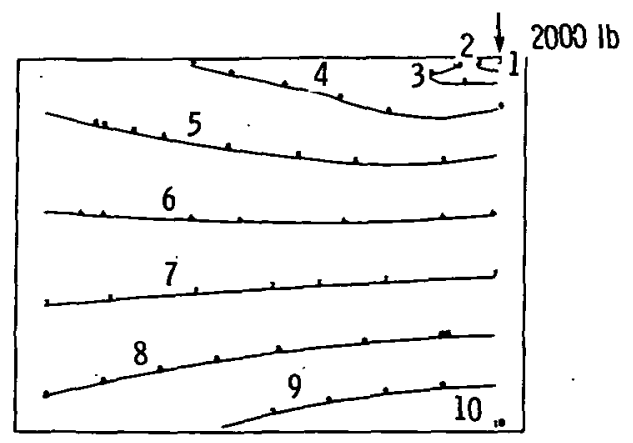

(b) Dynamic stress contours.

Figure 18 - Comparison of static and dynamic axial stress $\sigma_{x x}$ contours at peak load for $S$-glass/epoxy sinooth flexural specimens.
SYMBOL VALUES, pSI

$1-5.259623 \mathrm{E}+04$

$2-4.533239 E+04$

$3-3.806855 E+04$

$4-3.080471 E+04$

$5-2.354087 \mathrm{E}+04$

$6-1.627703 E+04$

$7-9.013191 \mathrm{E}+03$

$8-1.749351 E+03$

$9 \quad 5.514490 \mathrm{E}+03$

$10 \quad 1.277833 E+04$

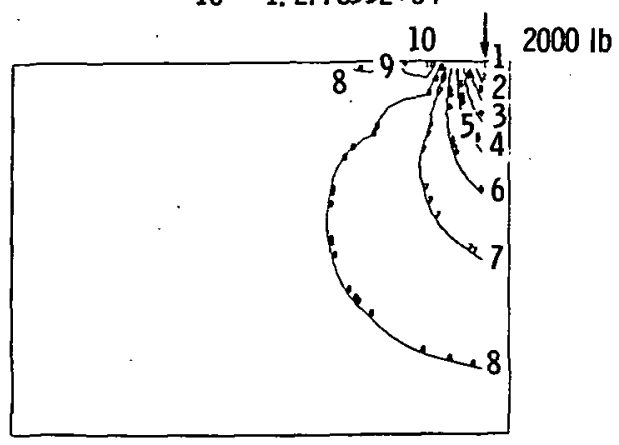

(a) Static stress contours.
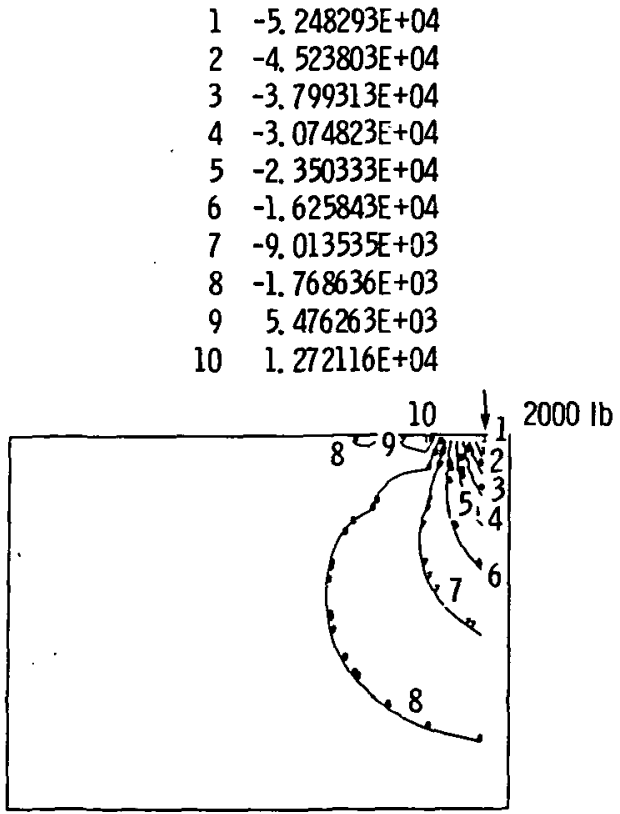

(b) Dynamic stress contours.

Figure 19. - Comparison of static and dynamic transverse normal stress $\sigma_{y y}$ contours at peak load for S-glass/epoxy smooth flexural specimen. 
SYMBOL VALUES, PSI

SYMBOL VALUES, pSi

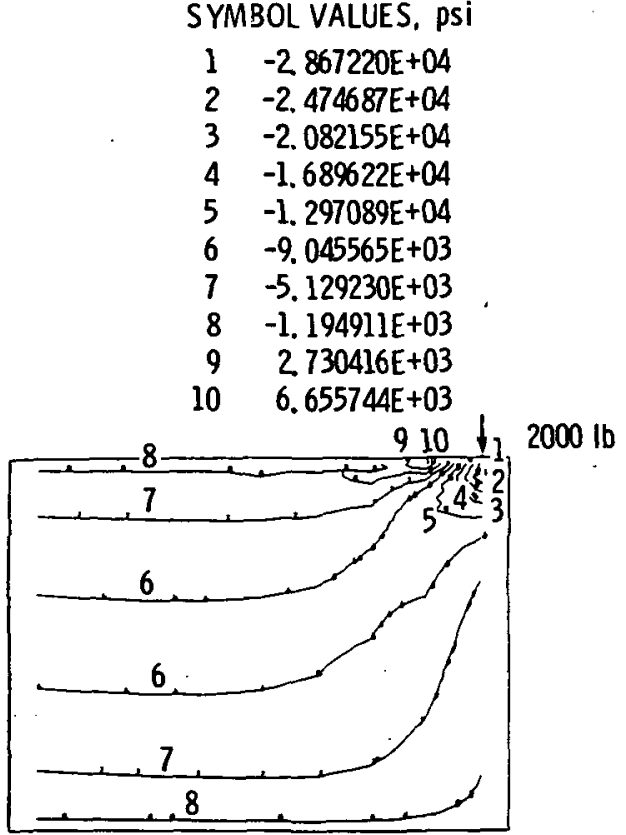

(a) Static stress contours.
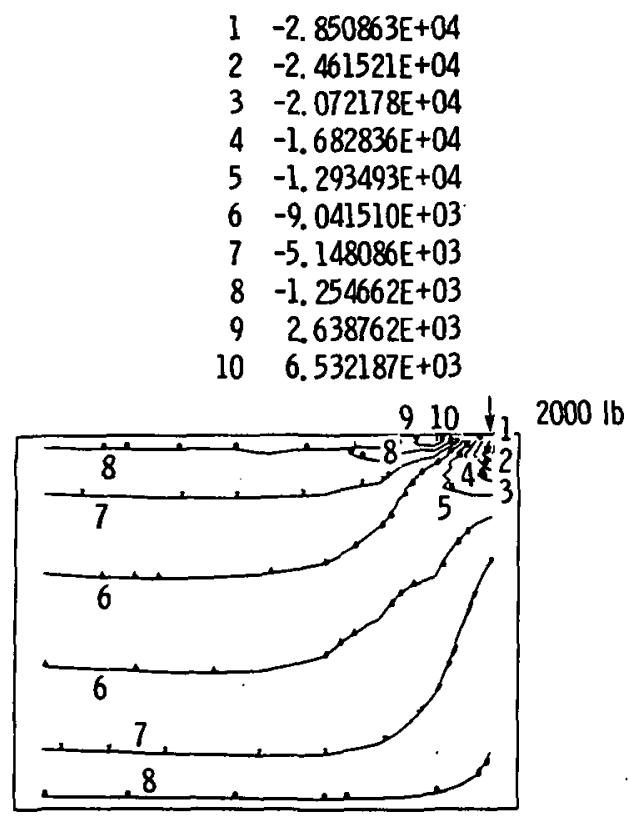

(b) Dynamic stress contours.

Figure 20. - Comparison of static and dynamic transverse shear stress $\sigma_{x y}$ contours at peak load for S-glass/epoxy smooth flexural specimen.
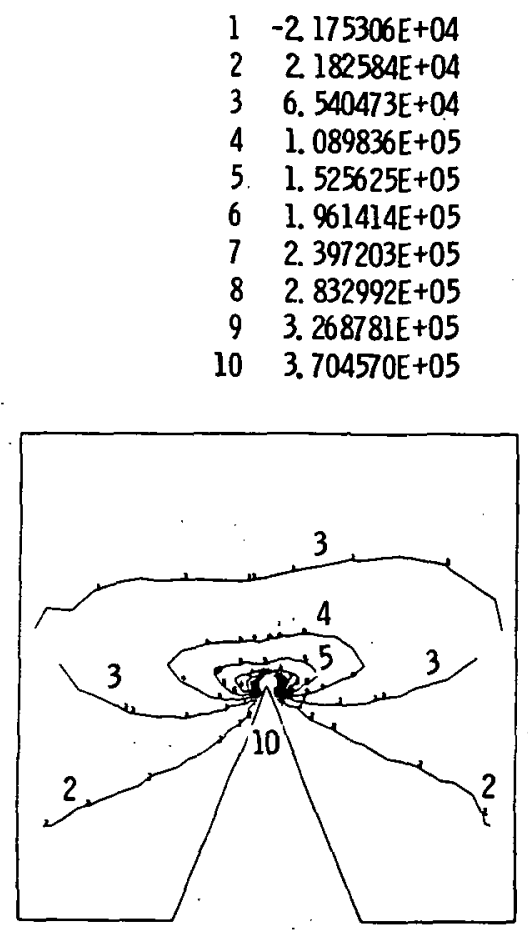

(a) Static stress contours.
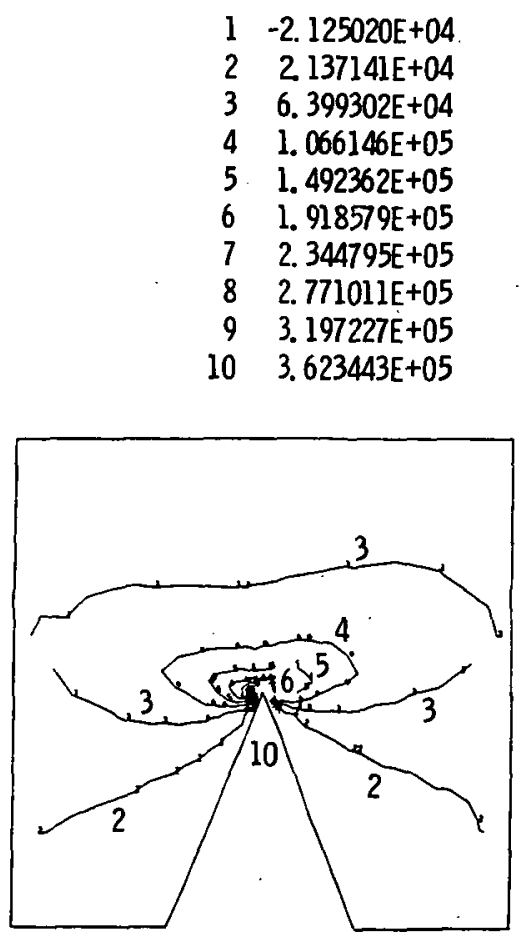

(b) Dynamic stress contours.

Figure 21. - Comparison of static and dynamic axial stress $\sigma_{x x}$ contours near the notch region at peak load for S-glass/epoxy notched flexural 
SYMBOL VALUES, pSi

$1-4.934123 E+03$

$29.081599 \mathrm{E}+03$

3. 2. $309732 \mathrm{E}+04$

3. $711304 E+04$

5. $112877 \mathrm{E}+04$

6. $514449 E+04$

7. $916021 \mathrm{E}+04$

9. $317593 E+04$

1. $071917 \mathrm{E}+05$

$10 \quad 1.212074 E+05$

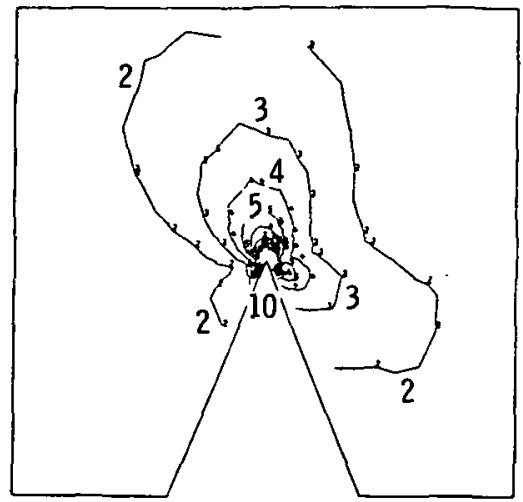

(a) Static stress contours.
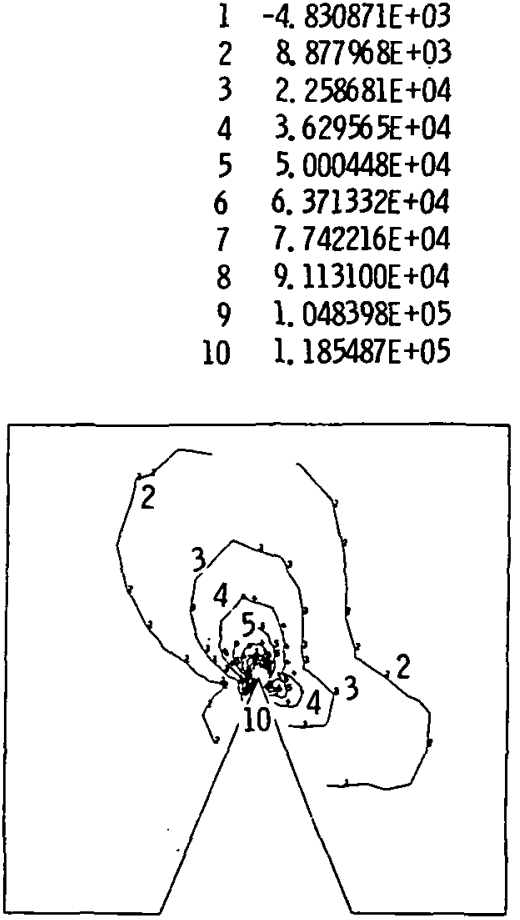

(b) Dynamic stress contours.

Figure 22. - Comparison of static and dynamic transverse normal stress $\sigma_{\text {yy }}$ contours near the notch region at peak load for S-glass/epoxy notched flexural specimen.
SYMBOL VALUES, psi

$1-9.067550 E+04$

$2-7.053295 E+04$

$3-5.039041 \mathrm{E}+04$

$4-3.024786 E+04$

$5-1.010531 E+04$

$6 \quad 1.003724 E+04$

$73.017979 E+04$

$85.032234 E+04$

$97.046488 \mathrm{E}+04$

$109.060743 \mathrm{E}+04$

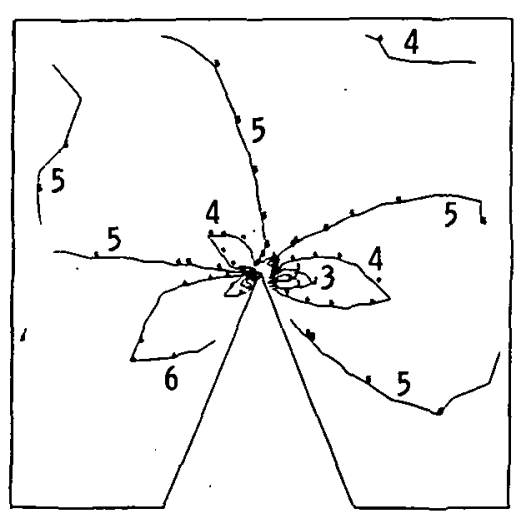

(a) Static stress contours.

$1-8.881748 \mathrm{E}+04$

$2-6.911646 E+04$

$3-4.941543 \mathrm{E}+04$

$4-2.971441 E+04$

$5-1.001339 E+04$

$69.687638 \mathrm{E}+03$

7 2. $938866 \mathrm{E}+04$

8 4. $908 \% 9 \mathrm{E}+04$

$9 \quad 6.879071 \mathrm{E}+04$

$108.849173 \mathrm{E}+04$

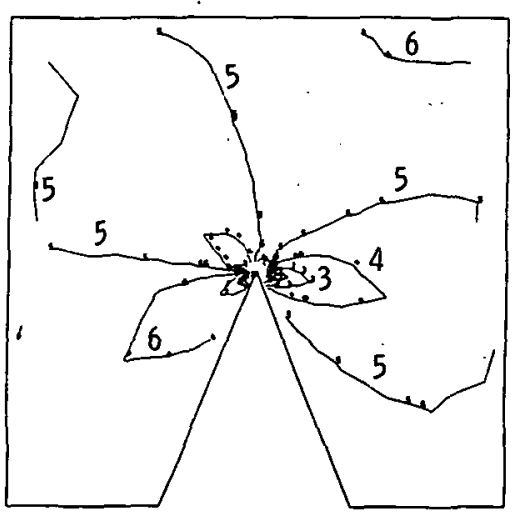

(b) Dynamic stress contours.

Figure 23. - Comparison of static and dynamic transverse shear stress $\sigma_{x y}$ contours near the notch region at peak load for S-glass/epoxy notched flexural specimen. 

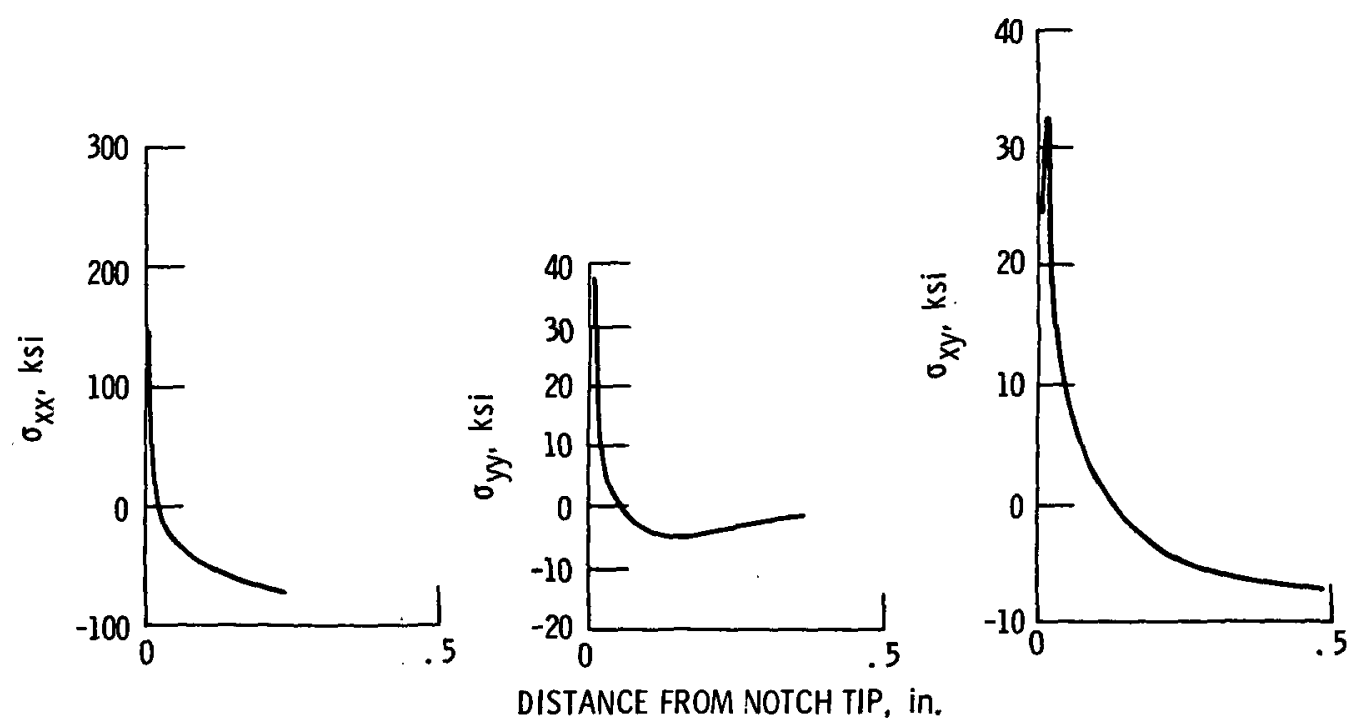

Figure 24. - Stress intensity distribution near the notch tip for S-glass/epoxy notched flexural specimen. 


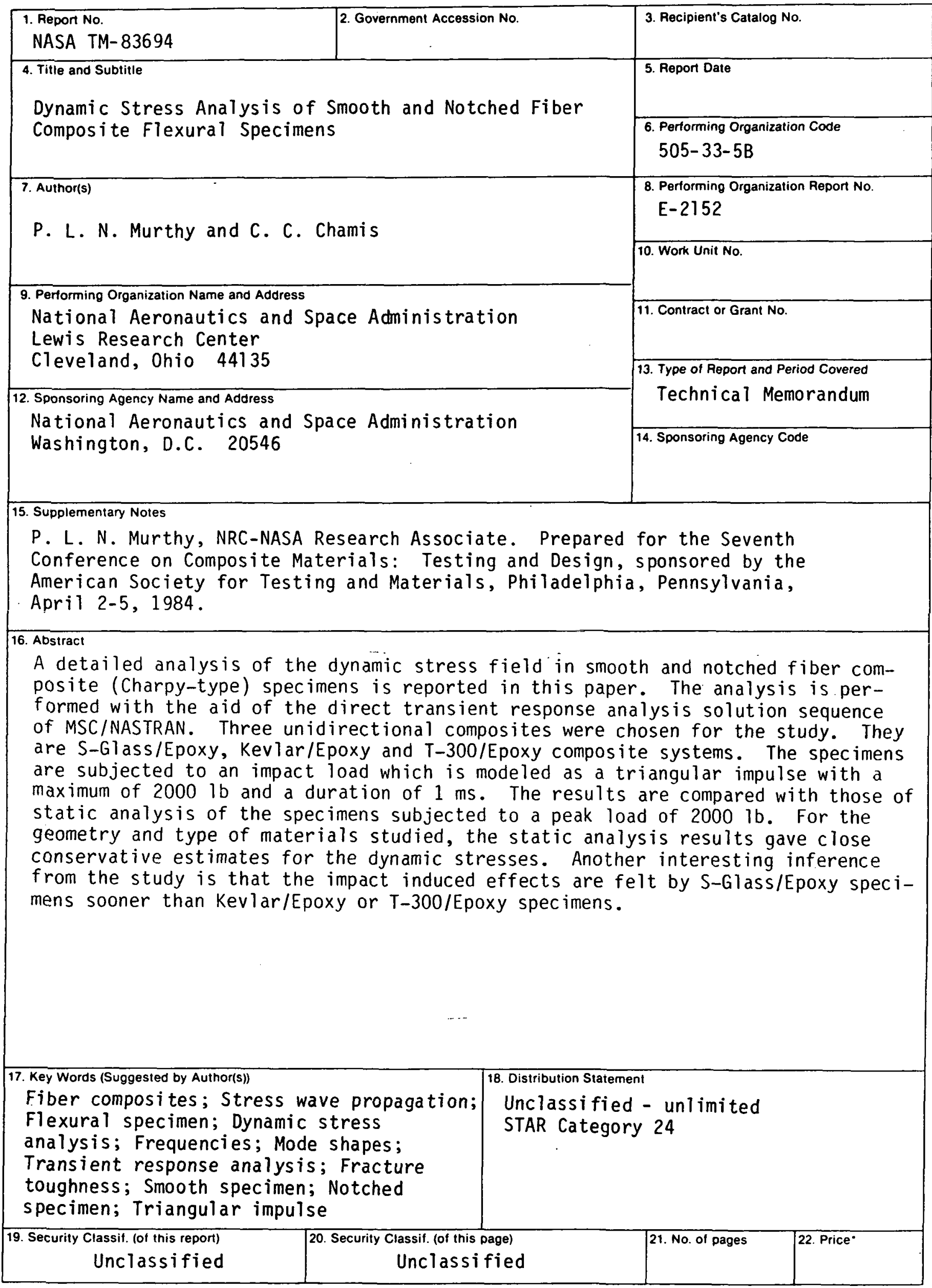

*For sale by the National Technical Information Service. Springfield. Virginia 22161 
National Aeronwutics and Space Administration

Washington, D.C.

20546

Officiol Busines

Penalty for Privete Un, 5000 recall founty class mall coox

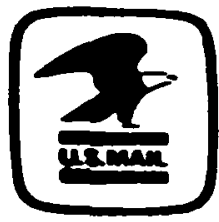

Pouthes and Fees Paid

Nationd Aeroneutics and

Spece Administrotion

MASA-451 